\title{
The Impact of Inter-organizational Social Capital in Collaborative Networks Competitiveness: An Empirical Analysis
}

\author{
Janaina Macke ${ }^{1}$, Rolando Vargas Vallejos ${ }^{2}$, Kadígia Faccin $^{3}$, and Denise Genari ${ }^{4}$ \\ ${ }^{1}$ TSO - Social Theory Research Group, University of Caxias do Sul, \\ R. Francisco Getúlio Vargas, 1130, \\ 95020-972 Caxias do Sul, RS, Brazil \\ jmacke@terra.com.br \\ ${ }^{2}$ rolandovvallejos@hotmail.com \\ ${ }^{3}$ kadigia@msn.com \\ ${ }^{4}$ denisegenari@hotmail.com
}

\begin{abstract}
With the social context of collaborative networks becoming increasingly important, research has broadened the traditional concept of competitiveness to include and emphasize 'soft' elements, like social capital. The social capital concept can be attained in two different contexts: intra and inter-groups. The objective of this study is to identify inter-organizational social capital elements and the relationship with collaborative network competitiveness. We intend to provide answers to these questions: (i) what are the elements that explain inter-organizational social capital? (ii) how are these elements related to competitiveness? (iii) what organizational characteristics facilitate social capital formation? A survey was conducted in the enterprises from the Brazilian Wine Industry Cluster. The data were analyzed using factorial analysis and bivariate correlations. The results point out three social capital factors that correspond to the social capital dimensions found in literature: structural, relational and cognitive. The research shows that the correlations among social capital dimensions and competitiveness are strong and significant, specially the structural and relational dimensions. Finally, implications for research and managerial practice were discussed.
\end{abstract}

Keywords: inter-organizational social capital, collaborative networks, competitiveness, Brazilian Wine Industry Cluster.

\section{Introduction}

Collaborative networks are organizational forms based on the collaboration between its members, according to a specific shared goal.

A collaborative network organization (CNO) is a form of emerging organizational setting that involves mutual engagement of participants to solve a problem together, which implies mutual trust, and therefore takes time, effort and dedication. A CNO can be created from a regional grouping of companies that already have a longstanding relationship and a cultural history [1]. 
The associative capacity depends on the degree that communities, groups and businesses share norms and values and are prepared to subordinate individual interests to those of larger groups. From these shared values trust emerges [2].

Collaborative networks organizations are structured primarily to make a favorable position against the competition. Therefore, internal resources presented in the group should be valued because they can become the source of competitive advantages [3], [4], [5], [6].

The resource-based view assumes that the most important variables are, in general, those that are less measurable and identifiable. We can see this statement in the case of social capital elements and the measurement difficulties. Moreover, internal resources become a source of competitive advantage when they have unique historical conditions, thus they are rare and difficult to imitate [7].

In this sense, social capital becomes a strongly competitive resource, enhancing the individual and collective capacity through the collaborative practices. Like the other forms of capital, it is productive, making possible the achievement of goals that would be unattainable without its existence becoming a public good [8], [9].

The present study aims to identify inter-organizational social capital elements and the relationship with collaborative network competitiveness. We intend to provide answers to these questions: (i) what are the elements that explain inter-organizational social capital? (ii) how are these elements related to competitiveness? (iii) what organizational characteristics facilitate social capital formation?

\section{Theoretical Background}

The social capital produces socio-cultural goods, in the form of emotions, feelings and relationships [10]. Social capital is the "sum of the actual and potential resources embedded within, available through and derived from the network of relationship possessed by an individual or social unit". The interaction between the agents of the network is what gives shape to relationships [11].

Many links form a dense network [12], with unique relational features [11], which positively affect the economic results and business competitive advantage [13], [14], [15]. When there is trust - the most important social capital element -, there is an expansion of horizontal contacts and consequently, business relationships [11]. The network formation involves interaction with a large number of people [7].

High levels of social capital enable better use of development opportunities [8], due to increased information that facilitate the action [16], [17].

Thus, confidence, stability, durability of relationships and the network density are key elements to high levels of trust and cooperation. These qualities also influence the clarity and visibility of mutual obligations [8], [11], [16].

In the study of Social Capital and its importance in the creation of intellectual capital, Nahapiet and Ghoshal [11] proposed three Social Capital dimensions, which are: structural, relational and cognitive. In the structural dimension of Social Capital we analyzed: the presence or not of relationships between the actors, the configuration or morphology of the network, describing the standards of connections, through variables as density, connectivity network configuration, stability and ties. 
The relational dimension describes the kind of personal relationship, developed through a history of interactions [12]. This concept focuses on aspects that influence the behaviors, like respect and friendship, which are going to decide on sociability, acceptance and prestige. Two actors can occupy similar positions in a network, however if their emotional and personal attitudes differ, their actions will be different in many aspects; therefore it is related to a behavioral component, which is revealed through facets as trust and distrust [17], [8], [18], norms [8], [16], obligations and expectations [16], [12] participation and diversity tolerance [11]. The third dimension of Social Capital, cognitive, refers to the resources that emanate shared visions, interpretations and systems of meaning, mainly codes and narratives, shared values and other cultural elements. Some authors affirm that this dimension is not being explored in the literature [11].

The social capital level presented in a network, facilitates member's access to opportunities and initiatives for collaborative action. Therefore, social capital can be considered the basic resource for a competitive strategy based on cooperation [7]. For the social capital flow among organizations, the presence of four main conditions is necessary such as time, interaction, interdependence and closure [11].

A collaborative network can be more competitive and have greater success when investing in two key elements that are: organizational culture and people (relationships). Firms within a network have a greater number of alliances and thus become more able to remain competitive and to introduce a complex repertoire of actions which aim competitiveness improvement [19].

\section{Methodological Aspects}

In order to evaluate inter-organizational social capital and its relations with competitiveness, we chose the survey technique of collecting data.

We made an extensive theoretical investigation from the literature of the most important studies on social capital [20], [11], 21], collaborative networks and competitiveness [22], [15]. After a meta-analysis phase, we started to build variables that could take part in an inter-organizational social capital survey, in the network context.

The final instrument version contains 66 variables divided into 3 blocks: i) social capital variables; ii) competitiveness variables and iii) control variables (number of employees, time dedicated to network activities, motivation to participate in the network, company revenue, length of association, gender, age, and educational level.

All items were measured using a five-point Likert scale (1=strongly disagree; $5=$ strongly agree). Before formal survey, we conducted semi-structured interviews with three experts in collaborative networks and social capital theory to validate our scale items. We also ran a pre-test with ten respondents.

A survey was conducted in the enterprises from the Brazilian Wine Industry Cluster (directors as respondents). The data were analyzed using factorial analysis and bivariate correlations. 


\section{Results: Context and Discussion}

One of the most prosperous Brazilian states, Rio Grande do Sul is known especially for its grain, wine production, cattle, agribusiness, and for its considerable industrial output. The main products exported by Rio Grande do Sul are shoes, tobacco, automobiles, grains, beef, leather, and chemical products.

The Serra Gaúcha, The Gaucho Highlands, is the mountainous region in the northeastern portion of Rio Grande do Sul state in southern Brazil. The wine cluster production of Serra Gaúcha is responsible for $80 \%$ of the national production.

Brazil occupies the 17 th position in the ranking of wine producers in the world. Figured as the fifth largest producer of the southern hemisphere, which includes countries of more recent production, exceeded only by Argentina, Australia, South Africa and Chile [23].

The number of wine companies in Rio Grande do Sul increased from 439 in 2001 to 682 companies in 2006, according to data from IBRAVIN (Brazilian Institute of Wine). Of the total 1.35 million tons of grapes produced in 2007 in the country, 705 thousand tones came from Rio Grande do Sul soil. The chain of grape and wine, represents an important part of the state's economy. It is estimated to exceed R\$ 1 billion Brazilian reais (US\$ 625 million dollars) [24].

The Brazilian wine industry is going through some difficulties. In addition to the unfavorable world stage with the intensification of global competition where wine producing countries implement aggressive strategic actions, there are internal adverse conditions in Brazil: (i) low consumption of wine per-capita (1.8 1/pp) compared to Argentina and Uruguay (30 1/pp); (ii) there is a lack in the culture: moderate drinking wine with meals; (iii) high incidence of taxes (42\% of the price), in Argentina and Chile remains at half of that [23].

However, some private and even government agencies stimulate the formation of collaborative networks in southern Brasil. Serra Gaúcha became the region where the formation of networks was eased up by the culture and the history of immigration bringing to light the culture of mutual assistance and cooperation for the local development. In addition to the networks of cooperation in this emerging industry, other agents form the basis for sustaining the wine industry such as higher education institutions and government agencies.

\subsection{An Inter-organizational Social Capital Instrument}

The data were submitted to factor analysis using PCA (Principal Component Analysis), with varimax rotation and treatment pairwise (considered all valid observations of each variable) for the missing data. The index of Kaiser-Meyer-Olkin (KMO) adequacy of the sample was 0.848 and the Bartlett's Test of Sphericity - (significant to 0.000 ) indicated the factorability of data.

The results of factor analysis suggested that social capital is shown by three factors, with $67.36 \%$ of total variance explained. The Cronbach's Alpha for this scale was 0.928 , that represents a very good range for an exploratory study [25]. It is possible to conclude that the items in each dimension of the construct are suitable for measuring the social capital in collaborative networks context (Table 1). 
Table 1. Inter-Organizational Social Capital Items and Results from the Brazilian Wine Industry Cluster

\begin{tabular}{|c|c|c|c|}
\hline Factor & Items & Loading & Mean \\
\hline \multirow{9}{*}{ 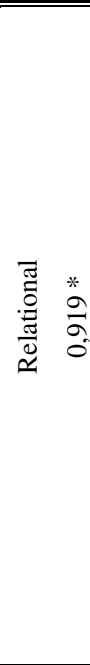 } & $\begin{array}{l}8 \text { - Even if my opinion is contrary to most other members of the } \\
\text { network, I feel comfortable to discuss it. }\end{array}$ & 0.801 & 3.65 \\
\hline & 12- The differences within the group do not affect the network. & 0.790 & 3.32 \\
\hline & $\begin{array}{l}15 \text { - Within the network, the members think and act in accordance } \\
\text { with the interests of all. }\end{array}$ & 0.697 & 3.31 \\
\hline & $\begin{array}{l}14 \text { - When I need help, I can count on other members of the } \\
\text { network. }\end{array}$ & 0.642 & 3.23 \\
\hline & $\begin{array}{l}21 \text { - Within the network there are several opportunities to exchange } \\
\text { information. }\end{array}$ & 0.621 & 3.13 \\
\hline & 18 - In the formal activities of the network, I do feel part of a group. & 0.600 & 3.63 \\
\hline & $\begin{array}{l}6 \text { - The similarities between participants facilitate the dynamics of } \\
\text { the network. }\end{array}$ & 0.567 & 3.26 \\
\hline & 11 - I identify with the members of the network. & 0.532 & 3.65 \\
\hline & $\begin{array}{l}10 \text { - The members of the network always seek to work together } \\
\text { through ideas, resources and information. }\end{array}$ & 0.487 & 3.51 \\
\hline \multirow{9}{*}{ 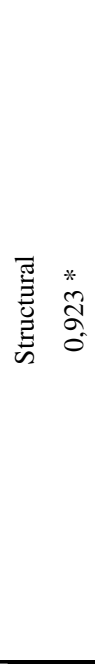 } & $\begin{array}{l}13 \text { - Problems of human resource development and training in my } \\
\text { company are often discussed in meetings of the network. }\end{array}$ & 0.806 & 2.40 \\
\hline & $\begin{array}{l}\text { 26- I have contact with members of the network at least once a } \\
\text { week. }\end{array}$ & 0.784 & 2.86 \\
\hline & 22 - I consider the members of the network my friends. & 0.705 & 3.71 \\
\hline & $\begin{array}{l}24 \text { - If I need some information for a decision, I know where to find } \\
\text { on the network. }\end{array}$ & 0.656 & 3.18 \\
\hline & $\begin{array}{l}2 \text { - The members of the network always share information with } \\
\text { others. }\end{array}$ & 0.638 & 3.38 \\
\hline & $\begin{array}{l}27 \text { - The network organizes group activities with our partners: } \\
\text { training, trade shows and events in general in the local community. }\end{array}$ & 0.612 & 3.26 \\
\hline & $\begin{array}{l}5 \text { - There are no barriers to communication between my company } \\
\text { and network partners in the exchange of professional knowledge. }\end{array}$ & 0.588 & 3.48 \\
\hline & $\begin{array}{l}25 \text { - The network is connected to other entities, as other networks of } \\
\text { businesses, unions, government agencies, among others. }\end{array}$ & 0.584 & 3.74 \\
\hline & $\begin{array}{l}4 \text { - I participate in the network because I agree with the purpose for } \\
\text { which it was created. }\end{array}$ & 0.561 & 3.93 \\
\hline \multirow{3}{*}{ 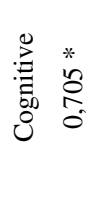 } & $\begin{array}{l}16 \text { - Most members of the network participate on events proposed } \\
\text { (meetings, exhibitions, lectures, seminars, trips, etc.). }\end{array}$ & 0.766 & 3.53 \\
\hline & $\begin{array}{l}3 \text { - The objective of the network is also clear to those not } \\
\text { participating in the network. }\end{array}$ & 0.755 & 2.85 \\
\hline & $\begin{array}{l}1 \text { - Most members know and agree with the objective of the } \\
\text { network. }\end{array}$ & 0.568 & 3.74 \\
\hline
\end{tabular}


Table 2. Competitiveness Items and Results from the Brazilian Wine Industry Cluster

\begin{tabular}{|c|c|c|c|}
\hline Factor & Items & Loading & Mean \\
\hline \multirow{7}{*}{ 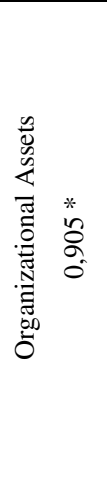 } & $\begin{array}{l}43 \text { - My company was able to provide higher quality products and } \\
\text { customer service after entering the network. }\end{array}$ & 0.783 & 3.39 \\
\hline & 36 - The network is very important to carry my business on. & 0.772 & 3.26 \\
\hline & $\begin{array}{l}37 \text { - When a problem occurs within the network, the members work } \\
\text { together to solve it. }\end{array}$ & 0.766 & 3.43 \\
\hline & $\begin{array}{l}35 \text { - My company acquired valuable contacts in participating in the } \\
\text { network. }\end{array}$ & 0.751 & 3.36 \\
\hline & $\begin{array}{l}32 \text { - If there is a conflict between members of the network, I offer to } \\
\text { mediate. }\end{array}$ & 0.732 & 3.32 \\
\hline & 34 - I feel motivated to participate in the network. & 0.674 & 3.38 \\
\hline & 42 - The leadership of the Network respects the views of all & 0.622 & 3.56 \\
\hline \multirow{6}{*}{ 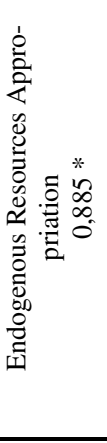 } & $\begin{array}{l}46 \text {-The network promotes regional events related to products and } \\
\text { services offered by the members. }\end{array}$ & 0.859 & 3.18 \\
\hline & $\begin{array}{l}47 \text {-The network contributes to the improvement of socio-cultural } \\
\text { issues related to members, relatives and the local community. }\end{array}$ & 0.821 & 3.08 \\
\hline & $\begin{array}{l}48 \text {-The network promotes awareness campaigns on environmental } \\
\text { conservation. }\end{array}$ & 0.661 & 3.31 \\
\hline & $\begin{array}{l}41 \text { - If there is a problem in the company of one of the members, } \\
\text { others work to solve it }\end{array}$ & 0.658 & 2.67 \\
\hline & $\begin{array}{l}40 \text { - The members of the network are encouraged to propose ideas } \\
\text { for change }\end{array}$ & 0.553 & 3.34 \\
\hline & $\begin{array}{l}45-\text { The network promotes actions that aim to enhance the tourism } \\
\text { in the region. }\end{array}$ & 0.547 & 3.77 \\
\hline \multirow{4}{*}{ 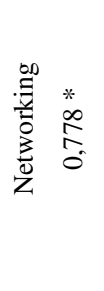 } & $\begin{array}{l}33 \text { - Within the network there are different types of skills such as } \\
\text { technical, managerial and social competences }\end{array}$ & 0.725 & 3.69 \\
\hline & $\begin{array}{l}31 \text { - I also have contact with members of the network outside the } \\
\text { formal activities of the same. }\end{array}$ & 0.575 & 3.63 \\
\hline & $\begin{array}{l}39 \text { - The members are responsible for bringing new business } \\
\text { opportunities to the network. }\end{array}$ & 0.564 & 3.38 \\
\hline & $\begin{array}{l}38 \text { - The activities of the network are aligned with the main } \\
\text { objective }\end{array}$ & 0.542 & 3.54 \\
\hline
\end{tabular}

As one contribution of this study, Table 1 shows the variables from final solution (as they appear in the questionnaire), in order to provide an inter-organizational social capital instrument.

By analyzing the emerged factors, we observed that they represent the dimensions of social capital theory: structural, relational and cognitive. The meaning of each factor can be inferred from the content.

In the case of Brazilian Wine Cluster, the social capital is represented mainly by the relational dimension, which explains $25.60 \%$ of the total variance. The structural dimension represents $25.28 \%$ and, finally, the cognitive dimension, explains $16.48 \%$ of the total variance. 
The results call attention to the fact that the levels of social capital variables are very similar, ranging from 2.40 to 3.74 . Similarly, average factors were close: for the cognitive dimension, 3.37 , for the structural dimension, 3.33 and for the relational, 3.41 .

We concluded that there is a high level of social capital in the cluster and a general balance among the three dimensions. In this perspective, we argued that the institutional structure of the network was effectively a conductor of the creation in social capital in the cluster, as discussed below.

\subsection{A Network Competitiveness Instrument}

Statistical analysis for competitiveness produced three factors that summarize the original set of observed variables. Together, the three factors explain $67.994 \%$ of the total variance.

As the measurement of capital, the responses of the indicator of competitiveness were also submitted to factorial analysis (PCA) with varimax rotation and pairwise treatment for the missing data. The index of Kaiser-Meyer-Olkin (KMO) adequacy of the sample was 0.868 and the Bartlett's Test of Sphericity - (significant to 0.000) indicated the factorability of data.

In the case of the Brazilian Wine Cluster, the competitiveness is represented mainly by the organizational assets, which explains $29.47 \%$ of the total variance. The endogenous resources appropriation represents $22.64 \%$ and, finally, the networking, explains $15.88 \%$ of the total variance. The total explained variance of the construct was, therefore, $67.99 \%$ (Table 2).

After building the scales of social capital and competitiveness to measure these constructs in the case of the wine cluster, we sought to examine whether there were significant relationships between the social capital level in a network and its competitiveness.

The Relational social capital showed the higher correlation with Endogenous Resources Appropriation, as well as Cognitive social capital. This indicates that a better use of local characteristics comes from the existence of ties among network participants. In the context of wine cluster many values are linked to the community, which may explain why correlation is also strongly associated with cognitive dimension (Table 3).

Table 3. Social Capital and Competitiveness Relations in the Brazilian Wine Industry Cluster

\begin{tabular}{l|c|c|c}
\hline \multicolumn{1}{c|}{ Factors } & $\begin{array}{c}\text { Relational social } \\
\text { capital }\end{array}$ & $\begin{array}{c}\text { Structured social } \\
\text { capital }\end{array}$ & $\begin{array}{c}\text { Cognitive social } \\
\text { capital }\end{array}$ \\
\hline \hline Organizational Assets & $0.796^{* *}$ & $0.860^{* *}$ & $0.460^{* *}$ \\
\hline Endogenous Resource Appropriation & $0.741^{* *}$ & $0.736^{* *}$ & $0.516^{* *}$ \\
\hline Networking & $0.692^{* *}$ & $0.743^{* *}$ & $0.396^{* *}$ \\
\hline
\end{tabular}

**. Correlation is significant at the 0.01 level. 
The Structural social capital provides the largest structural variations found in the dimension of Organizational Assets. It can be inferred that the network configuration determines the improvement of its competitiveness.

These results confirm the initial thesis that social capital is closely linked to the competitiveness improvement and the resource-based view defends that resources clearly provide competitive opportunities and high returns. In other words, the results show that social capital is indeed a kind of capital.

In addition, we observe that all three dimensions of social capital (cognitive, structural and relational) are based on information sharing as a mediator for use of resources that generate improvement in competitiveness.

Finally, the results support the theoretical arguments that the benefit of information is one of the key benefits of social capital, that information sharing contributes to business performance, and that different dimensions of social capital have different levels of influence on company performance.

\section{Final Considerations and Future Research}

The CNs have inter-organizational foundation as an example for the elimination of barriers created by the environment and/or other organizations, leading to an extensive network of collaboration among enterprises. In this case, a network can be understood as an organizational structure in which members that have dimensional, structural and financial limitations, cannot ensure the necessary conditions for survival and development alone.

Some convergent features within the members of a network are: i) the existence of more than two companies that, even collaborating with one another, remain independent, ii) the development of collective efficiency to obtain competitive advantages and overcome weaknesses and individual limitations, iii) the establishment of long-term relationship, iv) the openness to new participants who will contribute to reach the group goals. The network is usually linked to the freedom that individuals and/or organizations have to enter or leave the group, but makes possible to establish restrictions with the agreement of all members.

In order to represent the model that shows the social capital importance to competitiveness in CNs context, we adopted the idea of the intellectual capital mechanism, as Nahapiet and Ghoshal [11] used for the social capital and knowledge construction. The concept fits because this mechanism represents a continuous and dynamic process of combination and knowledge exchange (Figure 1).

The combination contributes to social capital creation through incremental changes and development of existing resources or radical changes and the combination of disconnected elements. Thus social capital can be promoted by radical or incremental resource combinations. The exchange process occurs when the parties involved have experience of joint activities, i.e., when individuals have lived the experience of working together as a team. We point out four conditions to the combination and to the exchange process: (i) the opportunity to make the combination or exchange; (ii) the worthwhile interactions; (iii) the motivation (receptivity to learning and new knowledge creation); and (iv) the combination capabilities (capacity to combine information or experience) [11]. 


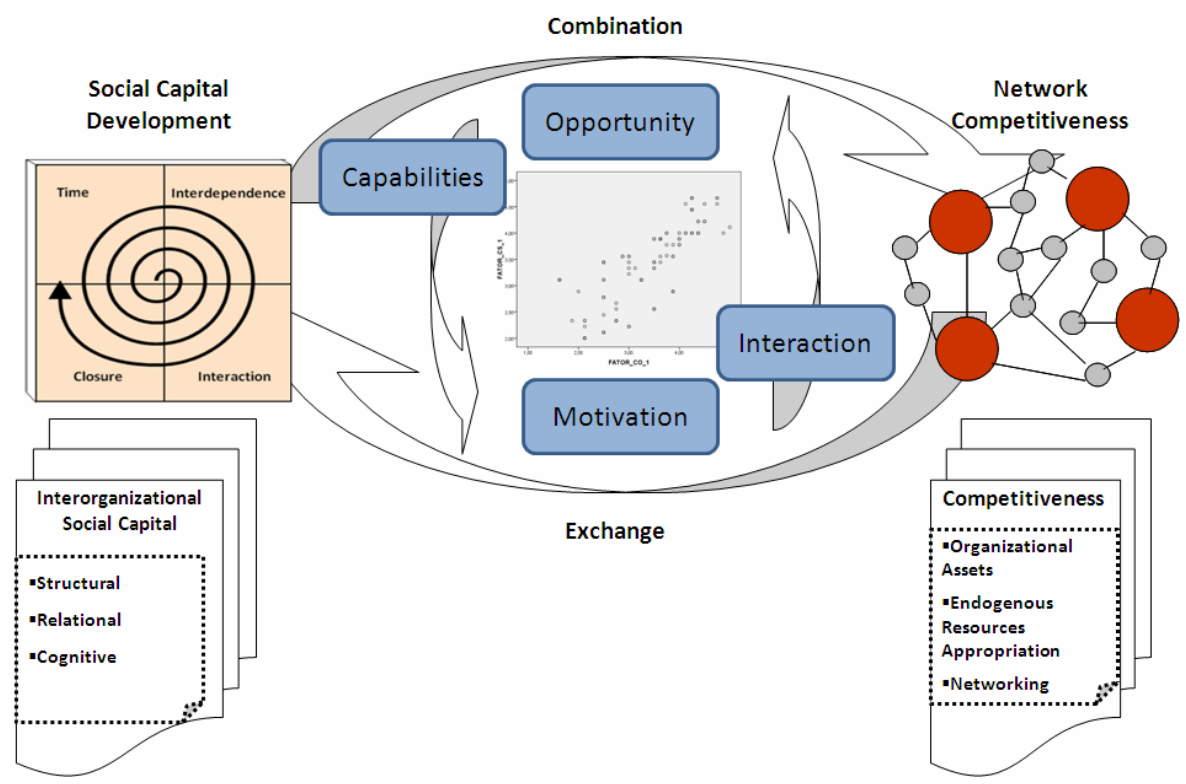

Fig. 1. Inter-organizational Social Capital and Competitiveness Model in Collaborative Networks Context

Finally, the importance of assessing social capital in collaborative networks can be summarized as: (i) high level of social trust and strong reciprocity norms, reduce the transaction costs; (ii) social networks attenuate the risks, allowing that their members engage more in innovations; (iii) social networks facilitate the fast information dissemination and with this, they reduce the asymmetries; and (iv) social networks allow that its members solve their collective problems easily.

Acknowledgments. This work is being supported by the University of Caxias do Sul (Universidade de Caxias do Sul - UCS), the Faculty of Technology TECBRASIL (Faculdade de Tecnologia TECBRASIL - FTec, and the National Counsel for Scientific and Technological Development (Conselho Nacional de Desenvolvimento Científico e Tecnológico - CNPq). We would also like to thank three unknown reviewers and our English teacher, Jane Dai-Prá.

\section{References}

1. Camarinha-Matos, L.M., Afsarmanesh, H.: The Virtual Enterprise Concept. In: Infrastructures for Virtual Enterprises: Networking Industrial Enterprises. Kluwer Academic Publishers, Boston (1999)

2. Fukuyama, F.: Trust: the social creation virtues and the creation of prosperity. Free Press, New York (1995)

3. Prahalad, C.K., Hamel, G.: The Core Competence of the corporation. Harward Business Review 68, 79-91 (1990) 
4. Barney, J.: Firm resources and sustained competitive advantage. Journal of Management, Greenwich 17(1), 99-120 (1991)

5. Penrose, E.T.: The Theory of the Growth of the Firm. Oxford University Press, New York (1995)

6. Wernerfelt, B.: A Resource-based view of the firm. Strategic Management Journal 5, 171180 (1984)

7. Macke, J., Sarate, J.A.R., Vallejos, R.V.: Collective Competence and Social Capital Analysis in Collaborative Networks. Journal of Systemics, Cybernetics and Informatics 8, 18-23 (2010)

8. Putnam, R.D., Leonardi, R., Nanetti, R.Y.: Making Democracy Work: civic traditions in modern Italy. Princeton University Press, Princeton (1993)

9. Arregle, J., Hitt, M.A., Sirmon, D., Very, P.: The Development of Organizational Social Capital: Attributes of Family Firms. Journal of Management Studies 44(1), 73-95 (2007)

10. Robison, L., Flora, J.: The Social Capital Paradigm: Bridging Across Disciplines. American Agricultural Economics Association 85(5), 1187-1193 (2003)

11. Nahapiet, J., Ghoshal, S.: Social capital, intellectual capital and the organizational advantage. Academy of Management Review 23(2), 242-266 (1998)

12. Granovetter, M.S.: The strength of weak ties. American Journal of Sociology 78, 1360 1380 (1973)

13. Sequeira, J.M., Rasheed, A.: Start-up and Growth of immigrant small businesses: the impact f social and human capital. Journal of Development Entrepreneurship 11(4), 357-375 (2006)

14. Watson, G.W., Papamarcos, S.: Social capital and organizational commitment. Journal of Business and Psychology 16(4), 537-552 (2002)

15. Wu, W.: Dimensions of Social Capital and Firm Competitiveness Improvement: The Mediating Role of Information Sharing. Journal of Management Studies 45(1), 122-146 (2008)

16. Coleman, J.S.: Capital in the creation of Human Capital. American Journal of Sociology 94, 95-120 (1988)

17. Fukuyama, F.: The great disruption: human nature and the reconstitution of social order. Profile Books, London (1999)

18. Putnam, R.D.: Bowling Alone: the collapse and revival of American community. Simon \& Schuster Paperbacks, New York (2000)

19. Vallejos, R.V., Macke, J., Olea, P.M., Toss, E.D.: Collaborative Networks and Social Capital: a theoretical and practical convergence. In: Camarinha-Matos, L.M., Picard, W. (eds.) Pervasive Collaborative Networks, pp. 43-52. Springer, Boston (2008)

20. Woolcock, M.: Social capital for social policy: lessons from international research and policy. In: Policy Research Conferation, Otawa (2005)

21. Onyx, J., Bullen, P.: Measuring Social Capital in Five Communities. The Journal of Applied Behavioral Science 36(1), 23-42 (2000)

22. Su, K., Lee, Y., Tsai, Y.: The paradigm of knowledge acquisition and social capital in engineering education: empirical research from Taiwanese universities. World Transactions on Engineering and Technology Education 4(1), 93-98 (2005)

23. Feinsterseifert, J.E.: The Emerging Brazilian Wine Industry. International Journal of Wine Business Research 19(3), 187-216 (2007)

24. IBRAVIN, Instituto Brasileiro do Vinho, Cadastro Vinícola, IBRAVIN/MAPA/SAA-RS, Bento Gonçalves, http: / / www. ibravin.org.br/index.php\#tomada_preco

25. Hair, J.F., Babin, B., Money, A.H., Samoul, P.: Essentials of Business Research Methods. Leyh Publishing, LLC (2003) 